\title{
Protective molecules and their cognate antibodies: new players in autoimmunity
}

\author{
Margherita Zen • Nicola Bassi • Carla Campana • Silvano Bettio • \\ Elena Tarricone $\bullet$ Linda Nalotto • Anna Ghirardello • Andrea Doria
}

Received: 1 September 2010 / Accepted: 8 September 2010

(C) Springer-Verlag 2010

\begin{abstract}
Impairment of the clearance of apoptotic material seems to contribute to autoantigen exposure, which can initiate or maintain an autoimmune response in predisposed individuals. Complement component C1q, Creactive protein $(\mathrm{CRP})$, serum amyloid $\mathrm{P}$ (SAP), mannose-binding lectin (MBL), apolipoprotein A-1 (Apo A1) and long pentraxin 3 (PTX3) are molecules involved in the removal of apoptotic bodies and pathogens, and in other antiinflammatory pathways. For this reason they have been called "protective" molecules. C1q has a key role in the activation of the complement cascade and acts as a bridging molecule between apoptotic bodies and macrophages favouring phagocytosis. In addition to other functions, CRP, SAP and MBL bind to the surface of numerous pathogens as well as cellular debris and activate the complement cascade, thus stimulating their clearance by immune cells. The role of PTX3 is more controversial. In fact, PTX also promotes the clearance of microorganisms, but the activation of the complement cascade through $\mathrm{C} 1 \mathrm{q}$ and removal of apoptotic material
\end{abstract}

$\overline{\text { M. Zen } \cdot \text { N. Bassi · C. Campana } \cdot \text { S. Bettio } \cdot \text { E. Tarricone } \cdot \text { L. Nalotto }}$ - A. Ghirardello Division of Rheumatology,

Department of Clinical and Experimental Medicine,

University of Padova, Italy

\section{A. Doria $(\varangle)$}

Division of Rheumatology,

Department of Clinical and Experimental Medicine,

University of Padova, Italy

E-mail: adoria@unipd.it can be either stimulated or inhibited by this molecule. Antibodies against protective molecules have been recently reported in systemic lupus erythematosus and other autoimmune rheumatic diseases. Some of them seem to be pathogenetic and others protective. Thus, protective molecules and their cognate antibodies may constitute a regulatory network involved in autoimmunity. Dysregulation of this system might contribute to the development of autoimmune diseases in predisposed individuals.

Keywords Autoimmunity - Apoptosis - Complement . Pentraxins - Autoantibodies

\section{Introduction}

The pathogenesis of autoimmune diseases is not yet completely understood. However, many studies have highlighted the key role of genetic, immunological, hormonal and environmental factors.

In the last few years cytoplasmatic and nuclear autoantigen exposure during cellular apoptosis and necrosis has been the subject of great interest.

The caspases are a group of proteases which are able to cleave other proteins after an aspartic acid residue. They can be subdivided in initiator caspases (caspase-2, -8, -9 and -10) and effector caspases (caspase-3, -6 and 7). Effector caspases, after activation by initiator caspases, trigger the cascade reaction responsible for programmed cell death. During these events important conformational changes in cellular structure occur, such as nuclear fragmentation and caspase-mediated activation of Rho-associated, coiled-coil containing protein kinase 1 (ROCK 1) which is responsible of bleb formation on 
the cell surface $[1,2]$. ROCK 1 is also responsible for the localization of nuclear fragments inside blebs which, if translocated to the cellular surface, can become targets for the immune response in autoimmune diseases such as systemic lupus erythematosus (SLE) [1, 2]. The following phases of apoptosis include the cellular fragmentation of apoptotic bodies, which are taken up by macrophages and other nonspecialized cells.

The impairment of the clearance of apoptotic material seems to contribute to autoantigen exposure, which can initiate or maintain an autoimmune response in predisposed individuals [3]. A critical role in the removal of apoptotic bodies and damaged cells is played by a group of molecules which includes complement component $\mathrm{C} 1 \mathrm{q}$, short pentraxins, $\mathrm{C}$-reactive protein (CRP) and serum amyloid $\mathrm{P}$ (SAP), mannose-binding lectin (MBL), apolipoprotein A1 (Apo A-1), and long pentraxin 3 (PTX3).

\section{C1q}

$\mathrm{C} 1 \mathrm{q}$ is one of the three subunits which form the first component of complement (C1). It is a glycoprotein of 460,000 kDa composed of six chains arranged in a "bouquet of tulips"-like structure with a C-terminal domain, called globular head, and an N-terminal domain (collagen-like domain). The globular head binds to the Fc region of immunoglobulins ( $\mathrm{Ig}$ ) $\mathrm{G}$ and $\mathrm{IgM}$, apoptotic cells, damaged cells, some pathogens, CRP, PTX3 and SAP; the collagen-like domain binds to the other two subunits of $\mathrm{C} 1(\mathrm{C} 1 \mathrm{r}$ and $\mathrm{C} 1 \mathrm{~s})$, and some surface receptors of macrophages (Fig. 1).
C1q is mostly produced outside the liver by monocytes, macrophages, fibroblasts, dendritic cells and epithelial cells [4]. Therefore the functions of C1q are related to its ability to bind to different molecules and receptors. It plays a key role in the activation of the complement cascade through the classic pathway: its binding to the $\mathrm{Fc}$ region of $\mathrm{Ig}$ activates $\mathrm{C} 1 \mathrm{r}$ and $\mathrm{C} 1 \mathrm{~s}$, leading to $\mathrm{C} 4$ cleavage by an enzymatic reaction [4]. $\mathrm{C} 1 \mathrm{q}$ acts as a bridging molecule between debris from cellular apoptosis (apoptotic bodies) and macrophages. The globular head recognizes "eat-me" signals such as phosphatidylserine, usually located on the internal surface of the cell membrane, which during apoptosis is translocated to the extracellular surface, and the collagen-like domain binds to phagocytes, such as macrophages, facilitating the uptake and removal of cellular debris derived from programmed cell death [5].

C1q shares some characteristics with collectins, which are a group of proteins, including MBL, produced by the liver. They bind to the oligosaccharidic structure of microorganisms activating complement and phagocytes and inhibiting microbial growth. It has been shown that $\mathrm{C} 1 \mathrm{q}$ binds to lipid A of the bacterial membrane, just like collectins, playing a role in the mechanisms of innate immunity [6]. C1q is also involved in adaptive immunity. The complement system, particularly the classic pathway, exerts a key role in preventing immune complex deposition on tissue [7]. It has been demonstrated that in patients affected with SLE there is a defect in the clearance of immune complex. In line with these observations, Botto et al. showed that C1q knockout mice can develop glomerulonephritis associated with impaired clearance of

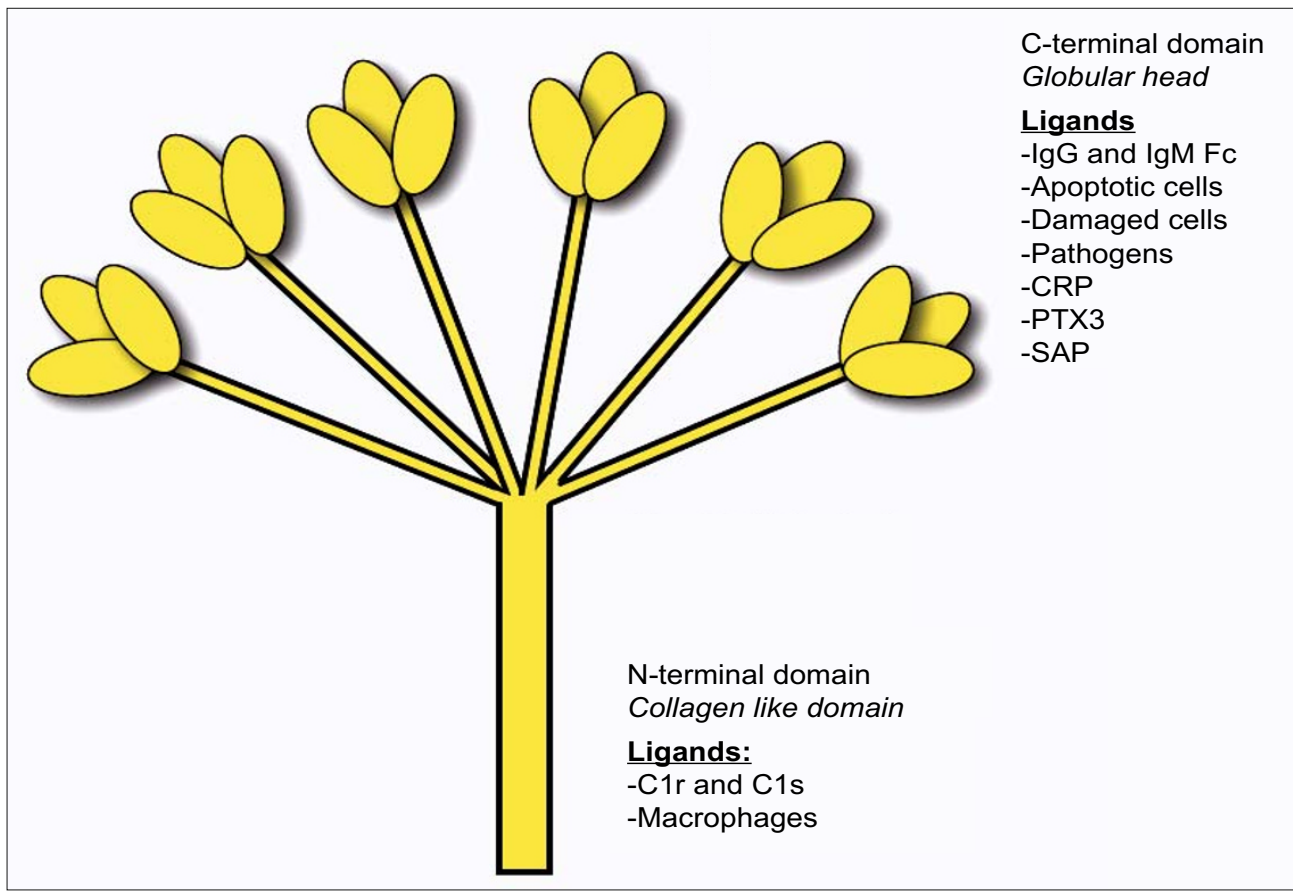

Fig. 1 "Bouquet of tulips" structure of C1q. CRP C reactive protein; $\mathrm{Clr}, \mathrm{Cl} q$ subunits of $\mathrm{C} 1$ complement fraction; PTX3 pentraxin 3; $S A P$ serum amyloid $P$ 
apoptotic cells, emphasizing the importance of $\mathrm{C} 1 \mathrm{q}$ in the removal of debris derived from cellular apoptosis and suggesting that the exposure of autoantigens during this process can play an important role in the development of autoimmunity [8, 9].

Rare cases of congenital deficiency of $\mathrm{C} 1 \mathrm{q}$ have been reported, whereas it is more frequent to find antibodies directed to $\mathrm{C} 1 \mathrm{q}$. Anti-C1q antibodies have been reported in many diseases including connective tissue diseases, rheumatoid vasculitis, Sjögren's syndrome and polyarteritis nodosa.

Marto et al. investigated the presence of anti-C1q antibodies in serum from a group of patients affected with SLE. This study showed the association between anti-C $1 \mathrm{q}$ and renal involvement, suggesting that these antibodies could help identify a subgroup of patients at high risk of developing glomerulonephritis [10]. Bijl et al. came to the same conclusion and showed that the reduced uptake of apoptotic bodies in SLE patients is not related to an intrinsic defect of macrophages, but results from complement deficiency (C1q, C3 and C4) [11]. Other studies have confirmed the high prevalence of antiC1q antibodies in patients affected with SLE, and their relationships with disease activity and renal flare [12-14].

\section{$\mathrm{C}$ reactive protein}

CRP is a protein belonging to the family of pentraxins, whose gene is located on the short arm of chromosome 1 (1q23). It consists of five identical nonglycosylated peptides of 206 aminoacids weighing $23 \mathrm{kDa}$ each arranged in a pentameric structure, typical of pentraxins. Each subunit has a binding site for phosphatidylcholine, while on the opposite side of the pentamer there is a binding site for $\mathrm{C} 1 \mathrm{q}$ [15]. Its name derives from its ability to bind to polysaccharide $\mathrm{C}$ of Streptococcus pneumoniae. It is synthesized by hepatocytes after stimulation by proinflammatory cytokines such as interleukin-1 (IL-1) and IL-6. CRP is considered a very useful marker of acute inflammation since its concentration is not affected by diet or circadian variations and its production is not influenced by diseases other than hepatic diseases [16-18]. CRP is an important effector of innate immunity since it binds to a large range of pathogens, damaged cells, chromatin, histones and apoptotic cells, thus activating the complement cascade and binding receptors for Ig on phagocytes.

The mean CRP levels in young adult blood donors is $0.8 \mathrm{mg} / \mathrm{l}$. After an acute stimulus the level can vary from $50 \mathrm{mg} / \mathrm{l}$ up to $500 \mathrm{mg} / \mathrm{l}$. Thus the detection of CRP can be a useful tool in diagnosis and monitoring of therapeutic response in infectious and inflammatory diseases [15]. CRP has the ability to bind to the surface of numerous pathogens (fungi, bacteria and yeasts) [19], and through $\mathrm{C} 1 \mathrm{q}$ it can activate the complement cascade favouring phagocytosis. Moreover, it has been demonstrated that even in the absence of complement, CRP can facilitate the phagocytosis of Staphylococcus aureus, Klebsiella aerogenes and Escherichia coli by leucocytes [20], interacting with the $\mathrm{Fc}$ gamma receptor $(\mathrm{Fc} \gamma \mathrm{R}) \mathrm{I}$ and II expressed on these cells [21, 22]. All these functions, along with neutrophil and monocyte activation mediated by CRP, explain the important role of CRP in immune responses.

CRP, as well as C1q, can stimulate the clearance of cellular debris derived from apoptosis. It binds to phosphatidylcholine on the cellular membrane in a calciumdependent manner, fibronectin, laminin, chromatin and histones, thus contributing to the activation of the classic complement pathway and favouring phagocytosis by macrophages $[15,23]$. CRP binds to SAP and this binding contributes to the activation of complement $[15,23]$.

It has been shown that CRP is a negative risk factor for cardiovascular events in both healthy individuals and patients affected with coronary artery disease; it also has a function as a biomarker to evaluate therapeutic response [24-28]. CRP has been reported to be expressed in atherosclerotic lesions where it could contribute to the formation of foam cells [25]. In fact, CRP could interact with the $3 \beta-\mathrm{OH}$ residue of cholesterol through its phosphatidylcholine binding site [29] and this binding could enhance the formation of foam cells. CRP stimulates superoxide production in smooth muscle cells of vessel walls [30]. It binds to oxidized lowdensity lipoprotein (oxLDL) and contributes to the migration of monocytes inside the plaque [31]; it might also promote the release of metalloproteinases [29] and tissue factor [32].

Two different conformations of CRP have been demonstrated, the pentameric native CRP molecule (nCRP) and the monomeric CRP molecule (mCRP), which seem to exert different effects $[33,34]$. In fact, it has been suggested that nCRP promotes atherosclerosis in apolipoprotein-E knockout mice [34] by binding oxLDL, activating the complement cascade, and favouring plaque formation, whereas mCRP inhibits atheroma formation by blocking complement activation [34]. These different effects exerted by the two CRP conformational states could explain the opposite results reported in some studies in humans and animal models [34-38].

CRP knockout mice have not been studied yet. AntiCRP antibodies have been reported in some diseases, such as SLE and primary biliary cirrhosis [35, 37]. In 
SLE correlations between anti-CRP antibodies and disease activity [39, 40] or cardiovascular diseases [40] have been observed. It is noteworthy that in SLE patients an increased risk of atherosclerosis has been reported [41], and myocardial infarction is one of the leading causes of death [42-46].

\section{Serum amyloid $\mathbf{P}$}

SAP is a highly preserved serum protein belonging to the pentraxin family whose gene is located on chromosome 1 very close to the gene for CRP. Its name derives from the constant presence of this protein in amyloid deposits. Its structure is similar to that of CRP with which it shares $50 \%$ of its aminoacid sequence. It consists of five subunits of 204 aminoacids each, which are arranged in a pentameric structure. As is CRP, SAP is also produced by the liver after stimulation of IL-1 and IL-6 [47].

SAP binds to many pathogens (bacteria and viruses), with a role against infections similar to that of CRP. SAP activates complement interacting with $\mathrm{C} 1 \mathrm{q}$ and binds to Fc $\gamma$ RI on leucocytes and, in contrast to CRP, also to FcyRIII [17, 20, 21, 48]. The ability of SAP to bind to chromatin, which is exposed on apoptotic bodies and blebs, is very important since it enhances phagocytosis of this cell debris, thus preventing the onset of autoimmune reactions. Notably, SAP knock out mice develop autoimmune reactions towards nuclear antigens, anti-DNA antibodies and glomerulonephritis when immunized with extrinsic chromatin [49].

It has been shown that there is an interaction between SAP and C1q. Indeed, SAP can induce complement activation by binding to $\mathrm{C} 1 \mathrm{q}$, leading to the removal of cellular debris through this pathway. Additionally, complement activation through $\mathrm{C} 1 \mathrm{q}$ contributes to the opsonization and phagocytosis of pathogens [16, 48].

A decrease in SAP activity and/or serum levels may be due to anti-SAP antibodies. A multicentre study by Zandman-Goddard et al. [50] demonstrated a high level of anti-SAP antibodies in SLE patients. The study also showed a correlation between antibody levels and disease activity measured by the SLE disease activity index (SLEDAI). Moreover, anti-SAP antibody levels have been shown to decrease after treatment, and this reduction is correlated with an increase in complement serum levels and clinical improvement [51].

\section{Mannose-binding lectin}

MBL is a serum protein with an oligomeric structure of approximately $400-700 \mathrm{kDa}$ which is produced by hepa- tocytes. Each molecule consists of two to six subunits of $32 \mathrm{kDa}$ each which are assembled in a "flower bouquet"like structure similar to $\mathrm{C} 1 \mathrm{q}$ (Fig. 2). Each subunit is formed by a collagen domain and a carbohydrate recognition domain (CRD) [51]. The molecule is active when four subunits are combined in a tetramer; dimers and trimers are inactive. As with $\mathrm{C} 1 \mathrm{q}$, when the MBL complex binds to a pathogen two MBL-associated proteases, MASP-1 and MASP-2, are activated leading to C4 and C2 cleavage and complement activation (Fig. 2). This complement activation pathway is called the "lectin pathway" [51].

MBL plays an important role in the clearance of microorganisms. It binds to gram-positive and gram-negative bacteria, viruses and fungi through CRD, and also binds to sugar residues on the surface of pathogens activating the complement cascade through the lectin pathway. MBL seems to confer a higher resistance against infections. Therefore, a deficiency of MBL is associated with a higher risk of developing an infectious disease particularly in the young. Notably, infections can trigger the development of autoimmune diseases [52]. MBL binds to sugars such as fucose and mannose which are on the outer surface of many microorganisms, but it does not recognize other sugars, such as sialic acid on the cellular surface of vertebrates. Most cells cannot bind to MBL since they express sialic acid residues on their mem-

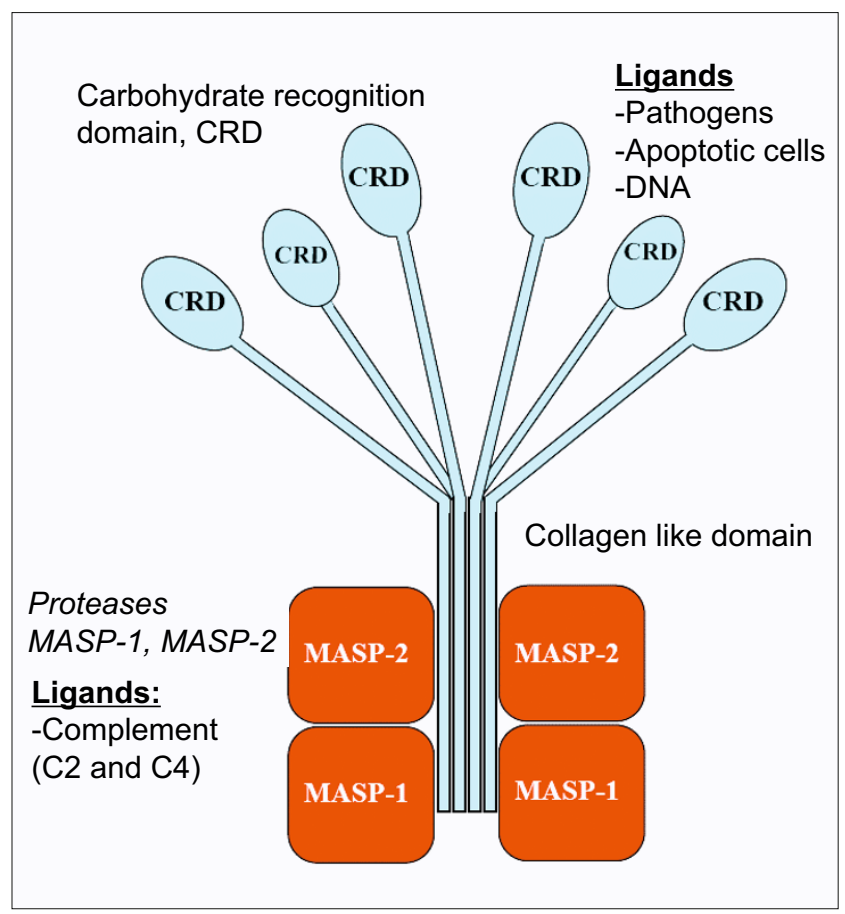

Fig. 2 Molecular flower bouquet structure of mannose-binding lectin (MBL). CRD carbohydrate recognition domain; $\mathrm{Clr}, \mathrm{Cl} q$ subunits of $\mathrm{C} 1$ complement fraction; MASP-1, MASP-2 MBL-associated proteases 
brane. Apoptotic cells lose these residues and express in their place sugar residues that are recognized by MBL. In this way MBL modulates and promotes the clearance of apoptotic cellular debris.

MBL seems to be involved in the pathogenesis of autoimmune diseases [53, 54]. By stimulating the clearance of cellular debris, MBL contributes to the decrease in expression of autoantigens, which can initiate or maintain an autoimmune response in predisposed individuals [51]. The role of MBL in autoimmunity is confirmed by the observation that MBL deficiency in patients with rheumatoid arthritis (RA) is associated with a bad prognosis, elevated IgM rheumatoid factor levels, increased articular erosions and poor therapeutic response [55-60]. Font et al. showed that SLE patients with a genetic deficiency of MBL developed greater organ damage [61]. A higher risk of developing SLE has been reported in patients with a deficiency of MBL due to a MBL gene polymorphism [62].

MBL deficiency is also associated with atherosclerosis in the general population. Even in SLE low MBL levels are associated with a higher risk of cardiovascular events $[63,64]$. Tsutsumi et al. suggested that the association between MBL deficiency and cardiovascular events in SLE could be due to an increased rate of some infections, such as infection with Chlamydia pneumoniae, which have been reported to correlate with coronary atherosclerosis and to increased disease activity and greater vascular damage observed in SLE patients with low MBL levels [65].

The association between MBL deficiency and peripheral thrombosis in patients with SLE has also been observed by Øhlenschlaeger et al. [66]. In this study, patients with a genetic deficiency of MBL had a higher risk of arterial thrombosis, suggesting the protective role of MBL for thrombotic events [66].

A decrease in MBL levels can be caused by genetic polymorphisms or by consumption due to inflammatory processes or autoantibodies. The presence of high titres of anti-MBL antibodies in patients affected with SLE, compared with healthy controls, has been reported; however, no relationship between antibody titre and disease activity has been found $[67,68]$.

\section{Apolipoprotein A-1}

Apo A-1 is a protein which contributes to the formation of high-density lipoprotein (HDL) complex. This complex exerts an important function in cholesterol metabolism since it binds to cholesterol in the periphery and transports it into the liver where it is excreted into bile. In this regard, Apo A-1 plays an essential role since it esterifies cholesterol and incorporates it in HDL, allowing its transport into the liver. In this function it acts as a cofactor of lecithin cholesterol acyl transferase in the reaction: lecithin + cholesterol $\rightarrow$ lysolecithin + cholesterol ester.

Therefore, it is clear that a deficiency of Apo A-1 and HDL is an important risk factor for atherosclerosis [16, 69].

Physical activity can efficiently increase Apo A-1 production through the increase in HDL playing a key role in the prevention of cardiovascular diseases. Notably, in the last few years many studies have been performed with the aim of testing synthetic HDL and Apo A-1 mimetic peptides as potential therapies for coronary heart diseases $[70,71]$.

During inflammation a decrease in Apo A-1 levels has been observed due to the effect of some cytokines such as IL-6, IL-1 $\beta$ and tumour necrosis factor alpha (TNF- $\alpha$ ), which inhibit the synthesis of this protein [16, 72]. For this reason Apo A-1 has been defined as a "negative" acute-phase protein since its levels decrease by $25 \%$ during an inflammatory process. It has been suggested that the HDL/Apo A-1 complex inhibits the binding between activated $\mathrm{T}$ lymphocytes and monocytes in the bloodstream, suppressing the release of IL-1 $\beta$ and TNF- $\alpha$, which exert antiinflammatory effects in both acute and chronic inflammation [73]. In fact, patients affected with RA have lower levels of circulating and synovial fluid Apo A-1 and HDL than healthy controls [74-76]. Thus, HDL seems to have a protective effect by controlling the inflammatory reaction.

Burger and Dayer suggested that the HDL/Apo A-1 complex may be the missing link between acute inflammation due to infection and chronic inflammation which can indeed be triggered by infection. In other words the reduction in HDL levels during an acute inflammatory process can contribute to a chronic inflammatory process in predisposed individuals [77].

Serum anti-Apo A-1 antibodies have been found in $32.5 \%$ of patients affected with SLE and in $23 \%$ of those with antiphospholipid antibody syndrome. These antibodies may perturb the balance between oxidants and antioxidants and reduce the activity of paraoxonase, an enzyme that is part of the HDL complex and can prevent the oxidation of LDL [78]. Furthermore, elevated titres of anti-Apo A1 and anti-HDL have been found in SLE patients with persistently high disease activity [79]. A correlation between anti-dsDNA antibodies and glomerulonephritis was also observed [79].

HDL leads to the production of nitric oxide stimulating the activity of nitric oxide synthase (eNOS). Thus anti-Apo A-1 antibodies, in a similar manner to antiHDL, seem to interfere with the antiatherogenic properties of HDL, increasing oxidative stress and, in turn, the risk of atherosclerosis in patients with SLE [80]. 


\section{Pentraxin 3}

PTX3 is a multimeric, glycosylated, protein of 381 aminoacids, which consists of eight identical protomers with a molecular weight of $40-50 \mathrm{kDa}$. It is organized into two distinct domains, a C-terminal one characterized by a high homology with CRP and SAP, and an N-terminal one, specific to PTX3 $[16,81]$. PTX3 is a member of the superfamily of pentraxins and plays a part in acute inflammatory reactions caused by trauma or infection. PTX3, differently from most other molecules, is produced by many cells, such as macrophages, dendritic cells, fibroblasts and activated endothelial cells, at the inflammatory site [81-83]. These cells produce and release PTX3 when stimulated by inflammatory mediators such as lipopolysaccharide, IL-1 and TNF- $\alpha$, which induce the NFKB promoter which is associated with the gene for PTX3 [81, 82].

Apart from de-novo production, neutrophils have been demonstrated to be a source of preformed PTX3 which is released when needed. Neutrophils store PTX3 in specific granules and are responsible for the rapid increase in PTX3. In a following stage the production derives from gene transcription [81, 82]. In conditions such as tissue damage (for example, myocardial infarction), infection or inflammatory diseases, PTX3 increases rapidly with a peak at 6-8 h from the acute event. For example, high levels of PTX3 in febrile patients with SLE who have either disease flare or infection have been reported [84].

Studies performed in mice have shown the importance of PTX3 in the defence against specific pathogens, emphasizing how PTX3 deficiency confers a higher susceptibility to infection by specific microorganisms (Aspergillus fumigatus, Pseudomonas aeruginosa, Salmonella typhimurium, Klebsiella pneumoniae, and cytomegalovirus) [85-87]. Mice with PTX3 deficiency are extremely susceptible to pulmonary aspergillosis and treatment with recombinant PTX3 has been shown to have a protective effect [88]. Moreover, it has recently been shown that the persistence of high levels of plasma PTX3 over the first days after the onset of severe sepsis and septic shock are associated with mortality [89]. Bozza et al. underlined the importance of PTX3 against viral infections. They found that mice with PTX3 deficiency are more prone to murine cytomegalovirus infection than wildtype mice [90]. In PTX3 knockout mice a higher mortality due to respiratory infections caused by Klebsiella pneumoniae (gram negative) has also been reported [91].

There are at least two different mechanisms by which PTX3 can protect from infection: it can bind to C1q activating the complement cascade or it can bind directly to some microorganisms while opsonizing them. The binding between C1q and PTX3 occurs on asparagin (Asn 220). The subsequent activation of the complement cas- cade contributes to the opsonization of pathogens and their phagocytosis by immune cells [92], thus stimulating the innate immune response. As an opsonizing factor, PTX3 directly stimulates phagocytosis of pathogens by macrophages [81, 93].

PTX3 also binds to cellular debris produced during cell apoptosis. The role of PTX3 in the removal of apoptotic debris is still controversial. It seems to inhibit the removal of apoptotic material by dendritic cells, but not by macrophages. Apoptotic bodies are opsonized by CRP, C1q and SAP which facilitate phagocytosis by specialized immune cells, while PTX3 binding to free C1q inhibits complement activation thus preventing an exaggerated and uncontrolled innate immune response [81].

Activation of macrophages and dendritic cells through Toll-like receptors induces the production and release of PTX3 from these cells. PTX3 acts, therefore, as a soluble mediator promoting the differentiation of $\mathrm{T}$ helper (Th) type 0 cells into Th1 rather than Th2 cells [88]. Thus, the production of PTX3 by dendritic cells through the stimulation of Toll-like receptors amplifies the resistance to innate immunity and promotes a shift towards adaptive immunity [87].

PTX3 stimulates macrophages to produce immunosuppressive cytokines (transforming growth factor beta and IL-10). IL-10 is an antiinflammatory cytokine able to inhibit the production of other cytokines such as Interferon gamma, IL-2, IL-3, TNF $\alpha$ and granulocytemacrophage colony-stimulating factor by macrophages and Th1 cells, and to decrease the expression of MHC II antigens and, therefore, antigen presentation [81, 82]. PTX3 is able to bind to fibroblast growth factor-2 (FGF2), which is a strong angiogenetic stimulating factor. FGF2 exerts a dual function since it can stimulate fibroblast migration and proliferation during inflammation and promote activation of smooth muscle cells of vessel walls and proliferation of endothelial cells during atherosclerosis. Accordingly, the binding between PTX3 and FGF2 inhibits these two functions [81, 82, 94]. PTX3 is also produced by macrophages ("foam cells") which are abundantly present inside plaques. Notably, PTX3 serum levels are elevated in patients with metabolic syndrome associated with subclinical atherosclerosis suggesting a correlation between PTX3 and the lipid profile, particularly between PTX3 and LDL [95].

Thus, PTX3 seems to be involved in the pathogenesis of atherosclerosis, but whether it exerts a protective or pathogenic role has not yet been completely clarified [94].

Antipentraxin 3 antibodies

Serum antibodies directed against PTX3 have recently been demonstrated. Augusto et al. found serum antibodies 
in 18 out of 36 patients affected with SLE (50\%), 1 out of 40 affected with RA and 4 out of 93 healthy controls [96]. We have recently reported high levels and prevalence of anti-PTX3 antibodies in a cohort of 130 SLE patients compared to 130 age- and sex-matched healthy subjects and 130 patients affected with other autoimmune diseases (27 RA, 26 polydermatomyositis, 26 systemic sclerosis, 26 Sjögren's syndrome, and 25 psoriatic arthritis) [97].

In addition to anti-PTX3 antibodies, we tested antibodies against a peptide from the central part of the whole molecule (PTX3_2). The levels and prevalence of anti-PTX3_2 antibodies were also higher in SLE patients than in controls [97].

It is still not clear if autoantibodies against molecules of innate immunity are really protective $[98,99]$ or pathogenic [81, 82]. Since in our study [97] circulating titres and prevalence of anti-PTX3 and anti-PTX3_2 antibodies were significantly lower in SLE patients with active glomerulonephritis than in those without renal involvement, we concluded that these antibodies might play a protective role, at least against glomerulonephritis.

By inhibiting the internalization of dying leucocytes by dendritic cells [100], PTX3 could inhibit the removal of apoptotic materials from the inflammation site, causing an impairment of autoantigen clearance and potentially contributing to autoantibody formation. The binding of anti-PTX3 antibodies to PTX3 might interfere with PTX3 function, having a protective effect on the tissue. Supporting this idea, intense staining for PTX3 is observed in the glomeruli of patients with various types of glomerulonephritis, while PTX3 expression is lacking in lupus glomerulonephritis [101], possibly revealing the binding of anti-PTX3 antibodies to PTX3 molecules.

\section{Conclusion}

Some molecules, called "protective" molecules, participate very actively in the apoptotic process facilitating the removal of cellular debris, thus inhibiting inflammatory necrosis. Autoantibodies directed against these molecule have been reported in SLE, a condition characterized by disturbed apoptosis. Some of these antibodies might be pathogenetic and others protective. Thus, protective molecules and their cognate antibodies may constitute a regulatory network which, if disturbed, might contribute to the development of autoimmune diseases in predisposed individuals.

Thanks to recent advances in technology [102], detection of these autoantibodies in an early phase of the autoimmune process might lead to the introduction of strategies for their manipulation with the aim of preventing autoimmunity [103-105].
Conflict of interest The authors declare that they have no conflict of interest relating to the publication of this manuscript.

\section{References}

1. Janko C, Schorn C, Grossmayer GE et al (2008) Inflammatory clearance of apoptotic remnants in systemic lupus erythematosus (SLE). Autoimmun Rev 8:9-12

2. Coleman ML, Sahai EA, Yeo M et al (2001) Membrane blebbing during apoptosis results from caspase-mediated activation of ROCK I. Nat Cell Biol 3(4):339-345

3. McPhillips KA, Erwig LP (2009) Assessment of apoptotic cell phagocytosis by macrophages. Methods Mol Biol 559:247-256

4. Sontheimer RD, Racila E, Racila DM (2005) C1q: its functions within the innate and adaptive immune responses and its role in lupus autoimmunity. J Invest Dermatol 125(1):14-23

5. Païdassi H, Tacnet-Delorme P, Garlatti V et al (2008) C1q binds to phosphatidylserine and likely acts as a multiligand-bridging molecule in apoptotic cell recognition. $\mathrm{J}$ Immunol 180(4):2329-2338

6. van de Wetering JK, van Golde LM, Batenburg JJ (2004) Collectins: players of the innate immune system. Eur J Biochem 271(7):1229-1249

7. Ahmed AE, Veitch J, Whaley K (1990) Mechanism of action of an inhibitor of complement-mediated prevention of immune precipitation. Immunology 70(2):139-144

8. Botto M (1998) C1q knock-out mice for the study of complement deficiency in autoimmune disease. Exp Clin Immunogenet 15(4):231-234

9. Botto M, Dell'Agnola C, Bygrave AE et al (1998) Homozygous $\mathrm{C} 1 \mathrm{q}$ deficiency causes glomerulonephritis associated with multiple apoptotic bodies. Nat Genet 19(1):56-59

10. Marto N, Bertolaccini ML, Calabuig E et al (2005) Anti-C1q antibodies in nephritis: correlation between titres and renal disease activity and positive predictive value in systemic lupus erythematosus. Ann Rheum Dis 64(3):444-448

1 1. Bijl M, Reefman E, Horst G et al (2006) Reduced uptake of apoptotic cells by macrophages in systemic lupus erythematosus: correlates with decreased serum levels of complement. Ann Rheum Dis 65(1):57-63

12. Sinico RA, Radice A, Ikehata M et al (2005) Anti-C1q autoantibodies in lupus nephritis: prevalence and clinical significance. Ann N Y Acad Sci 1050:193-200

13. Trendelenburg M (2005) Antibodies against C1q in patients with systemic lupus erythematosus. Springer Semin Immunopathol 27(3):276-285

14. Moroni G, Radice A, Giammarresi G et al (2009) Are laboratory tests useful for monitoring the activity of lupus nephritis? A 6year prospective study in a cohort of 228 patients with lupus nephritis. Ann Rheum Dis 68(2):234-237

15. Pepys MB, Hirschfield GM (2003) C-reactive protein: a critical update. J Clin Invest 111(12):1805-1812

16. Szyper Kravitz M, Shoenfeld Y (2006) Autoimmunity to protective molecules: is it the perpetuum mobile (vicious cycle) of autoimmune rheumatic diseases? Nat Clin Pract Rheumatol 2:481-490

17. Szyper Kravitz M, Pitashny M, Shoenfeld Y (2005) Protective molecules - C-reactive protein (CRP), serum amyloid P (SAP), pentraxin3 (PTX3), mannose-binding lectin (MBL), and apolipoprotein A1 (Apo A1), and their autoantibodies: prevalence and clinical significance in autoimmunity. J Clin Immunol 25:582-591

18. Castrejón I, Ortiz AM, García-Vicuña R et al (2008) Are the Creactive protein values and erythrocyte sedimentation rate equi- 
valent when estimating the 28 -joint disease activity score in rheumatoid arthritis? Clin Exp Rheumatol 26(5):769-775

19. Szalai AJ (2002) The antimicrobial activity of C-reactive protein. Microbes Infect 4(2):201-205

20. Kindmark CO (1971) Stimulating effect of C-reactive protein on phagocytosis of various species of pathogenic bacteria. Clin Exp Immunol 8(6):941-948

21. Bharadwaj D, Mold C, Markham E et al (2001) Serum amyloid $\mathrm{P}$ component binds to $\mathrm{Fc}$ gamma receptors and opsonizes particles for phagocytosis. J Immunol 166(11):6735-6741

22. Mold C, Baca R, Du Clos TW (2002) Serum amyloid P component and C-reactive protein opsonize apoptotic cells for phagocytosis through Fcgamma receptors. J Autoimmun 19(3): 147-154

23. Gershov D, Kim S, Brot N et al (2000) C-Reactive protein binds to apoptotic cells, protects the cells from assembly of the terminal complement components, and sustains an antiinflammatory innate immune response: implications for systemic autoimmunity. J Exp Med 192(9):1353-1364

24. Ridker PM, Paynter NP, Rifai N et al (2008) C-reactive protein and parental history improve global cardiovascular risk prediction: the Reynolds Risk Score for men. Circulation 118(22):2243-2251

25. Bucova M, Bernadic M, Buckingham T (2008) C-reactive protein, cytokines and inflammation in cardiovascular diseases. Bratisl Lek Listy 109(8):333-340

26. Aukrust P, Halvorsen B, Yndestad A et al (2008) Chemokines and cardiovascular risk. Arterioscler Thromb Vasc Biol 28(11):1909-1919

27. Gonzalez-Gay MA, Llorca J, Garcia-Unzueta MT et al (2008) High-grade inflammation, circulating adiponectin concentrations and cardiovascular risk factors in severe rheumatoid arthritis. Clin Exp Rheumatol 26(4):596-603

28. Bultink IE, Turkstra F, Diamant M et al (2008) Prevalence of and risk factors for the metabolic syndrome in women with systemic lupus erythematosus. Clin Exp Rheumatol 26(1):32-38

29. Taskinen S, Hyvönen M, Kovanen PT et al (2005) C-reactive protein binds to the 3beta-OH group of cholesterol in LDL particles. Biochem Biophys Res Commun 329(4):1208-1216

30. Du Clos TW, Mold C (2004) C-reactive protein: an activator of innate immunity and a modulator of adaptive immunity. Immunol Res 30(3):261-277

31. Singh U, Dasu MR, Yancey PG et al (2008) Human C-reactive protein promotes oxidized low density lipoprotein uptake and matrix metalloproteinase-9 release in Wistar rats. J Lipid Res 49(5):1015-1023

32. Bhakdi S, Torzewski M, Paprotka K et al (2004) Possible protective role for $\mathrm{C}$-reactive protein in atherogenesis: complement activation by modified lipoproteins halts before detrimental terminal sequence. Circulation 109(15):1870-1876

33. Khreiss T, Jozsef L, Potempa LA et al (2004) Conformational rearrangement in C-reactive protein is required for proinflammatory actions on human endothelial cells. Circulation 109(16):2016-2022

34. Schwedler SB, Amann K, Wernicke K et al (2005) Native Creactive protein increases whereas modified C-reactive protein reduces atherosclerosis in apolipoprotein E-knockout mice. Circulation 112(7):1016-1023

35. Bassi N, Zampieri S, Ghirardello A et al (2009) Pentraxins, antipentraxins antibodies, and atherosclerosis. Clin Rev Allerg Immunol 37(1):36-43

36. Keenan RT, Swearingen CJ, Yazici Y (2008) Erythrocyte sedimentation rate and $\mathrm{C}$-reactive protein levels are poorly correlated with clinical measures of disease activity in rheumatoid arthritis, systemic lupus erythematosus and osteoarthritis patients. Clin Exp Rheumatol 26(5):814-819
37. Meyer O (2010) Anti-CRP antibodies in systemic lupus erythematosus. Joint Bone Spine. DOI: 10.1016/j.jbspin.2010.04.010

38. Wetterö J, Nilsson L, Jonasson L, Sjöwall C (2009) Reduced serum levels of autoantibodies against monomeric $\mathrm{C}$-reactive protein (CRP) in patients with acute coronary syndrome. Clin Chim Acta 400(1-2):128-131

39. Sjöwall C, Bengtsson AA, Sturfelt G et al (2004) Serum levels of autoantibodies against monomeric C-reactive protein are correlated with disease activity in systemic lupus erythematosus. Arthritis Res Ther 6(2):R87-R94

40. O’Neill SG, Isenberg DA, Rahman A (2007) Could antibodies to C-reactive protein link inflammation and cardiovascular disease in patients with systemic lupus erythematosus? Ann Rheum Dis 66:989-991

41. Valdivielso P, Gómez-Doblas JJ, Macias M et al (2008) Lupusassociated endothelial dysfunction, disease activity and arteriosclerosis. Clin Exp Rheumatol 26(5):827-833

42. Avalos I, Rho YH, Chung CP et al (2008) Atherosclerosis in rheumatoid arthritis and systemic lupus erythematosus. Clin Exp Rheumatol 26(5 Suppl 51):S5-S13

43. Doria A, Sherer Y, Meroni PL et al (2005) Inflammation and accelerated atherosclerosis - basic mechanisms. Rheum Dis Clin N Am 31:329-354

44. Doria A, Shoenfeld Y, Pauletto P (2004) Premature coronary disease in systemic lupus. N Engl J Med 350(15):1571-1575

45. Doria A, Shoenfeld Y, Wu R et al (2003) Risk factors for subclinical atherosclerosis in a prospective cohort of patients with systemic lupus erythematosus. Ann Rheum Dis 62:1071-1077

46. Doria A, Iaccarino L, Ghirardello A et al (2006) Long-term prognosis and causes of death in systemic lupus erythematosus. Am J Med 119:1497-1499

47. Emsley J, White HE, O’Hara BP et al (1994) Structure of pentameric human serum amyloid $\mathrm{P}$ component. Nature 367(6461):338-345

48. Mold C, Gresham HD, Du Clos TW (2001) Serum amyloid P component and C-reactive protein mediate phagocytosis through murine Fc gamma Rs. J Immunol 166(2):1200-1205

49. Bickerstaff MC, Botto M, Hutchinson WL et al (1999) Serum amyloid $\mathrm{P}$ component controls chromatin degradation and prevents antinuclear autoimmunity. Nat Med 5(6):694-697

50. Zandman-Goddard G, Blank M, Langevitz P et al (2005) Antiserum amyloid component $\mathrm{P}$ antibodies in patients with systemic lupus erythematosus correlate with disease activity. Ann Rheum Dis 64(12): 1698-1702

51. Saevarsdottir S, Vikingsdottir T, Valdimarsson H (2004) The potential role of mannan-binding lectin in the clearance of selfcomponents including immune complexes. Scand J Immunol 60(1-2):23-29

52. Avcin T, Canova M, Guilpain P et al (2008) Infections, connective tissue diseases and vasculitis. Clin Exp Rheumatol 26(1 Suppl 48):S18-S26

53. Ramos-Casals M, Brito-Zerón P, Soria N et al (2009) Mannosebinding lectin-low genotypes are associated with milder systemic and immunological disease expression in primary Sjögren's syndrome. Rheumatology (Oxford) 48(1):65-69

54. Gupta B, Raghav SK, Agrawal C et al (2006) Anti-MBL autoantibodies in patients with rheumatoid arthritis: prevalence and clinical significance. J Autoimmun 27(2):125-133

55. Saevarsdottir S, Vikingsdottir T, Vikingsson A et al (2001) Low mannose binding lectin predicts poor prognosis in patients with early rheumatoid arthritis. A prospective study. J Rheumatol 28(4):728-734

56. Ip WK, Lau YL, Chan SY et al (2000) Mannose-binding lectin and rheumatoid arthritis in southern Chinese. Arthritis Rheum 43(8):1679-1687

57. Graudal NA, Homann C, Madsen HO et al (1998) Mannan bin- 
ding lectin in rheumatoid arthritis. A longitudinal study. J Rheumatol 25(4):629-635

58. Garred P, Madsen HO, Marquart H et al (2000) Two edged role of mannose binding lectin in rheumatoid arthritis: a cross sectional study. J Rheumatol 27(1):26-34

59. Jacobsen S, Madsen HO, Klarlund M et al (2001) The influence of mannose binding lectin polymorphisms on disease outcome in early polyarthritis. TIRA Group. J Rheumatol 28(5):935-942

60. Graudal NA, Madsen HO, Tarp U et al (2000) The association of variant mannose-binding lectin genotypes with radiographic outcome in rheumatoid arthritis. Arthritis Rheum 43(3):515-521

61. Font J, Ramos-Casals M, Brito-Zerón P et al (2007) Association of mannose-binding lectin gene polymorphisms with antiphospholipid syndrome, cardiovascular disease and chronic damage in patients with systemic lupus erythematosus. Rheumatology (Oxford) 46(1):76-80

62. Lee YH, Witte T, Momot T et al (2005) The mannose-binding lectin gene polymorphisms and systemic lupus erythematosus: two case-control studies and a meta-analysis. Arthritis Rheum 52(12):3966-3974

63. Best LG, Ferrell RE, Decroo S et al (2009) Genetic and other factors determining mannose-binding lectin levels in American Indians: the Strong Heart Study. BMC Med Genet 10:5

64. Hegele RA, Ban MR, Anderson CM et al (2000) Infectionsusceptibility alleles of mannose-binding lectin are associated with increased carotid plaque area. J Investig Med 48(3):198-202

65. Tsutsumi A, Takahashi R, Sumida T (2005) Mannose binding lectin: genetics and autoimmune disease. Autoimmun Rev 4(6):364-372

66. Øhlenschlaeger T, Garred P, Madsen HO et al (2004) Mannosebinding lectin variant alleles and the risk of arterial thrombosis in systemic lupus erythematosus. N Engl J Med 351(3):260-267

67. Mok MY, Jack DL, Lau CS et al (2004) Antibodies to mannose binding lectin in patients with systemic lupus erythematosus. Lupus 13(7):522-528

68. Seelen MA, Trouw LA, van der Hoorn JW et al (2003) Autoantibodies against mannose-binding lectin in systemic lupus erythematosus. Clin Exp Immunol 134(2):335-343

69. Van Craeyveld E, Lievens J, Jacobs F et al (2009) Apolipoprotein A-I and lecithin: cholesterol acyltransferase transfer induce cholesterol unloading in complex atherosclerotic lesions. Gene Ther 16(6):757-765

70. Mendez AJ (2010) The promise of apolipoprotein A-I mimetics. Curr Opin Endocrinol Diabetes Obes 17(2):171-176

71. Bailey D, Jahagidar R, Gordon A et al (2010) RVX-208: a small molecule that increases apolipoprotein A-I and high-density lipoprotein cholesterol in vitro and in vivo. J Am Coll Cardiol 55(23):2580-2589

72. Papadakis JA, Sidiropoulos PI, Karvounaris SA et al (2009) High prevalence of metabolic syndrome and cardiovascular risk factors in men with ankylosing spondylitis on anti-TNFalpha treatment: correlation with disease activity. Clin Exp Rheumatol 27(2):292-298

73. Hyka N, Dayer JM, Modoux C et al (2001) Apolipoprotein A-I inhibits the production of interleukin-1beta and tumor necrosis factor-alpha by blocking contact-mediated activation of monocytes by T lymphocytes. Blood 97(8):2381-2389

74. Park YB, Lee SK, Lee WK et al (1999) Lipid profiles in untreated patients with rheumatoid arthritis. J Rheumatol 26(8):1701-1704

75. Doherty NS, Littman BH, Reilly K et al (1998) Analysis of changes in acute-phase plasma proteins in an acute inflammatory response and in rheumatoid arthritis using two-dimensional gel electrophoresis. Electrophoresis 19(2):355-363

76. Oliviero F, Sfriso P, Baldo G et al (2009) Apolipoprotein A-I and cholesterol in synovial fluid of patients with rheumatoid arthritis, psoriatic arthritis and osteoarthritis. Clin Exp Rheumatol 27(1):79-83

77. Burger D, Dayer JM (2002) High-density lipoprotein-associated apolipoprotein A-I: the missing link between infection and chronic inflammation? Autoimmun Rev 1(1-2):111-117

78. Batuca JR, Ames PR, Isenberg DA et al (2007) Antibodies toward high-density lipoprotein components inhibit paraoxonase activity in patients with systemic lupus erythematosus. Ann N Y Acad Sci 1108:137-146

79. O'Neill SG, Giles I, Lambrianides A et al (2010) Antibodies to apolipoprotein A-I, high-density lipoprotein, and C-reactive protein are associated with disease activity in patients with systemic lupus erythematosus. Arthritis Rheum 62(3):845-854

80. Batuca JR, Ames PR, Amaral M et al (2009) Anti-atherogenic and anti-inflammatory properties of high-density lipoprotein are affected by specific antibodies in systemic lupus erythematosus. Rheumatology (Oxford) 48(1):26-31

81. Ortega-Hernandez OD, Bassi N, Shoenfeld Y et al (2009) The long pentraxin 3 and its role in autoimmunity. Semin Arthritis Rheum 39(1):38-54

82. Mantovani A, Garlanda C, Doni A et al (2008) Pentraxins in innate immunity: from C-reactive protein to the long pentraxin PTX3. J Clin Immunol 28(1):1-13

83. Nauta AJ, Bottazzi B, Mantovani A et al (2003) Biochemical and functional characterization of the interaction between pentraxin 3 and C1q. Eur J Immunol 33(2):465-473

84. Kim J, Koh JK, Lee EY et al (2009) Serum levels of soluble triggering receptor expressed on myeloid cells-1 (sTREM-1) and pentraxin 3 (PTX3) as markers of infection in febrile patients with systemic lupus erythematosus. Clin Exp Rheumatol 27(5):773-778

85. Reading PC, Bozza S, Gilbertson B et al (2008) Antiviral activity of the long chain pentraxin PTX3 against influenza viruses. J Immunol 180(5):3391-3398

86. Sprong T, Peri G, Neeleman C et al (2009) Pentraxin 3 and Creactive protein in severe meningococcal disease. Shock 31(1):28-32

87. He X, Han B, Liu M et al (2007) Long pentraxin 3 in pulmonary infection and acute lung injury. Am J Physiol Lung Cell Mol Physiol 292(5):L1039-L1049

88. Garlanda C, Hirsch E, Bozza S et al (2002) Non-redundant role of the long pentraxin PTX3 in anti-fungal innate immune response. Nature 420(6912):182-186

89. Mauri T, Bellani G, Patroniti N et al (2010) Persisting high levels of plasma pentraxin 3 over the first days after severe sepsis and septic shock onset are associated with mortality. Intensive Care Med 36(4):621-629

90. Bozza S, Bistoni F, Gaziano R et al (2006) Pentraxin 3 protects from MCMV infection and reactivation through TLR sensing pathways leading to IRF3 activation. Blood 108(10):3387-3396

91. Soares AC, Souza DG, Pinho V et al (2006) Dual function of the long pentraxin PTX3 in resistance against pulmonary infection with Klebsiella pneumoniae in transgenic mice. Microbes Infect 8(5):1321-1329

92. Inforzato A, Peri G, Doni A et al (2006) Structure and function of the long pentraxin PTX3 glycosidic moiety: fine-tuning of the interaction with $\mathrm{C} 1 \mathrm{q}$ and complement activation. Biochemistry 45(38):11540-11551

93. Franz S, Gaipl US, Munoz LE et al (2006) Apoptosis and autoimmunity: when apoptotic cells break their silence. Curr Rheumatol Rep 8(4):245-247

94. Camozzi M, Zacchigna S, Rusnati M et al (2005) Pentraxin 3 inhibits fibroblast growth factor 2-dependent activation of smooth muscle cells in vitro and neointima formation in vivo. Arterioscler Thromb Vasc Biol 25:1837-1842

95. Zanetti M, Bosutti A, Ferreira C et al (2009) Circulating pentra- 
xin 3 levels are higher in metabolic syndrome with subclinical atherosclerosis: evidence for association with atherogenic lipid profile. Clin Exp Med 9(3):243-248

96. Augusto JF, Onno C, Blanchard S et al (2009) Detection of antiPTX3 autoantibodies in systemic lupus erythematosus. Rheumatology (Oxford) 48(4):442-444

97. Bassi N, Ghirardello A, Blank M et al (2010) IgG anti-pentraxin 3 antibodies in systemic lupus erythematosus. Ann Rheum Dis 69(9):1704-1710

98. Sherer Y, Gorstein A, Fritzler MJ et al (2004) Autoantibody explosion in systemic lupus erythematosus: more than 100 different antibodies found in SLE patients. Semin Arthritis Rheum 34:501-537

99. Sjowall C, Wettero J (2007) Pathogenic implications for autoantibodies against $\mathrm{C}$-reactive protein and other acute phase proteins. Clin Chim Acta 378:13-23
100. Rovere P, Peri G, Fazzini F et al (2000) The long pentraxin PTX3 binds to apoptotic cells and regulates their clearance by antigen presenting dendritic cells. Blood 96:4300-4306

101. Bussolati B, Peri G, Salvidio G et al (2003) The long pentraxin PTX3 is synthesized in IgA glomerulonephritis and activates mesangial cells. J Immunol 170:1466-1472

102. Lalvani A, Meroni PL, Millington KA et al (2008) Recent advances in diagnostic technology: applications in autoimmune and infectious diseases. Clin Exp Rheumatol 26(1 Suppl 48):S62-S66

103. Doria A, Briani C (2008) Primary prevention of systemic lupus erythematosus. Nat Clin Pract Rheumatol 4(11):576-577

104. Doria A, Arienti S, Rampudda M et al (2008) Preventive strategies in systemic lupus erythematosus. Autoimmun Rev 7:192-197

105. Doria A, Briani C (2008) Lupus: improving long-term prognosis. Lupus 17:166-170 